\title{
Multifaceted allergen avoidance during infancy reduces asthma during childhood with the effect persisting until age 18 years
}

\author{
Martha Scott, ${ }^{1,2}$ Graham Roberts, ${ }^{1,2}$ Ramesh J Kurukulaaratchy, ${ }^{1,2}$ Sharon Matthews, ${ }^{1}$ \\ Andrea Nove, ${ }^{1}$ S Hasan Arshad ${ }^{1,2}$
}

\begin{abstract}
- Additional materials are published online only. To view these files please visit the journal online

(http://dx.doi.org/10.1136/ thoraxjnl-2012-202150)

${ }^{1}$ The David Hide Asthma and Allergy Research Centre, St Mary's Hospital, Newport, Isle of Wight, UK

${ }^{2}$ Clinical and Experimental

Sciences, Faculty of Medicine, University of Southampton, UK
\end{abstract}

\section{Correspondence to}

Professor S Hasan Arshad, The David Hide Asthma and Allergy Research Centre, St Mary's Hospital, Newport, Isle of Wight P030 5TG, UK:

sha@soton.ac.uk

Received 11 May 2012 Accepted 6 July 2012 Published Online First 2 August 2012

\section{ABSTRACT}

Background Asthma is a chronic disease that often starts in childhood. The key risk factors are a child's environment and their genetic characteristics. The aim of this study was to evaluate the efficacy of environmental modification in the first 12 months of life on the prevalence of asthma in high-risk individuals.

Methods Children $(n=120)$ considered at high risk of allergic disorders (either dual heredity or single heredity and a high cord total $\lg \mathrm{E}$ ), were enrolled in a singleblinded, randomised controlled trial. Infants in the intervention arm were either breast fed with the mother on a low allergen diet or given an extensively hydrolysed formula. Exposure to house dust mite allergen was reduced. The control group followed standard advice. Children were assessed at ages 1, 2, 4, 8 and 18 years for the presence of asthma and atopy.

Results At 18 years of age, there was a significantly lower prevalence of asthma in the prevention group compared with the control group (OR: $0.23,95 \% \mathrm{Cl} 0.08$ to $0.70, p=0.01$ ), primarily due to asthma that developed during childhood but persisted until age 18 years. Repeated-measure analysis showed that there was an overall reduction in asthma prevalence from 1 to 18 years (OR: $0.51, \mathrm{Cl} 0.32$ to $0.81, p=0.04$ ). Prevalence of atopy was not significantly different between the two groups at age 18 .

Conclusion Comprehensive allergen avoidance in the first year of life is effective in preventing asthma onset in individuals considered at high risk due to heredity. The effect occurs in the early years, but persists through to adulthood.

\section{INTRODUCTION}

Over the last 50 years, the prevalence of asthma has increased dramatically, with an estimated global occurrence of 300 million. ${ }^{1}$ Despite intensive efforts to develop novel therapeutic agents, asthma is still an incurable disease with pharmacotherapy at best achieving abeyance of symptoms. Research has highlighted the importance of the interaction of gene and environment, particularly in the early years of life. ${ }^{2}$ Atopy is arguably the most significant single risk factor for asthma with a populationattributable risk of $56 \%$ in some, but not all populations. ${ }^{3}$ Environmental factors represent an opportunity for intervention in asthma prevention. ${ }^{4}$ House dust mite exposure (HDM), ${ }^{5}$ dietary

\section{Key messages}

What is the key question?

- Can asthma be prevented by allergen avoidance during infancy?

What is the bottom line?

- A comprehensive allergen-avoidance regime in high-risk infants during infancy reduced asthma onset during childhood.

\section{Why read on?}

- This is the only primary prevention study of asthma, which shows a positive outcome throughout childhood.

intake, ${ }^{6}$ microbial $^{7}$ and viral exposures ${ }^{8}$ are potential factors influencing asthma onset. Optimal timing of primary prevention is unknown, but early life immunological development in atopic infants, ${ }^{9}$ and evidence of airway changes consistent with asthma in infants, ${ }^{10}$ argues for early intervention within the first few months of life. Further, early sensitisation to HDM has been consistently associated with childhood asthma. ${ }^{11}$

We hypothesised that in infants genetically predisposed to atopy, allergen avoidance of both house dust mites and common food allergens during infancy may lead to a reduction in the development of allergic diseases with the benefit continuing beyond the actual period of avoidance. Consequently, 120 infants were recruited into this intervention study in 1990 and assessed the ages of 1, 2, 4 and 8 years. Outcomes at these follow-ups have been reported previously and have shown significant reduction in asthma, eczema and atopy in the intervention group. ${ }^{12-16}$ We now report the outcome of this randomised controlled trial examining the preventive effect of a multifaceted allergen avoidance strategy in the first year of life.

\section{METHODS}

Detailed descriptions of the intervention methodology have been published previously. ${ }^{12}$ Briefly, in 1990, 120 infants who were considered at high risk of developing allergic disease on the basis of dual heredity (two or more immediate family members (parents and/or sibling) with an allergic disorder) or 
Figure 1 Consort diagram of the study.

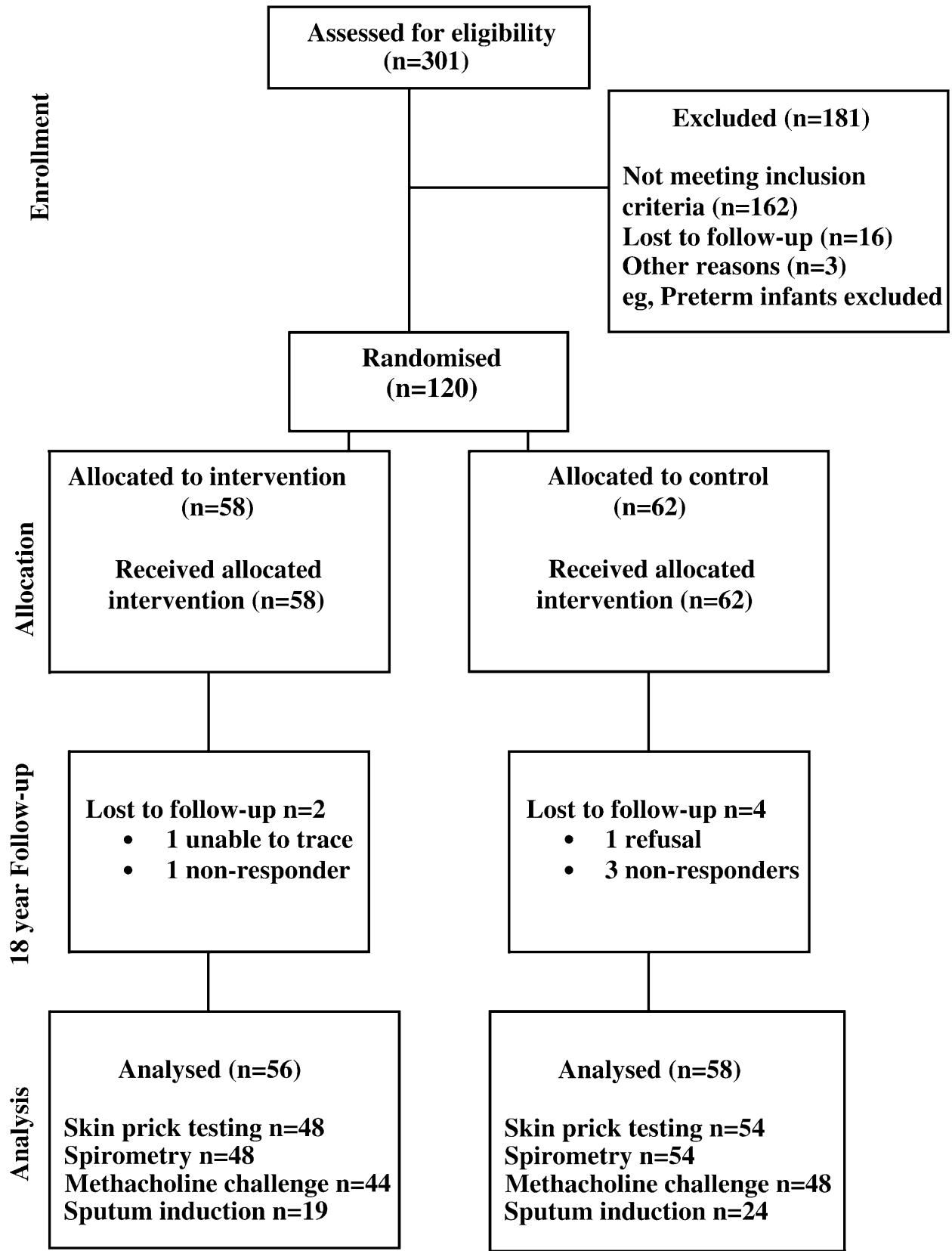

single heredity (one parent or sibling with an allergic disorder) plus cord total IgE $>0.5 \mathrm{kU} / \mathrm{l}$ were recruited at birth. Participants were randomised into a prevention group $(n=58)$ and a control group $(n=62)$ using computer-generated random allocation numbers. ${ }^{12}$ The study was single-blinded, so that the participants' grouping was concealed from the researchers until after assessment at each follow-up. From birth until 12 months, lactating mothers and infants in the prevention arm followed a diet of strict avoidance of: dairy products, egg, soya, fish and shellfish, peanut and tree nuts. HDM reduction measures were taken, including vinyl mattress covers and use of acaricide in bedrooms and living rooms. Dust samples collected at 0 and 9 months showed that the prevention group had significantly lower levels of HDM than the control group (median Der p1 $5.86 \mu \mathrm{g} / \mathrm{g}$ (interquartile range $3.55-10.93$ ) vs $15.31 \mu \mathrm{g} / \mathrm{g}$ (7.25-27.49), $\mathrm{p}<0.0001)$. The control group was provided with standard recommendations prevalent at the time. A $100 \%$ follow-up was achieved at 1, 2, 4 and 8 years of age. Assessments consisted of parental questionnaires regarding symptoms of asthma and allergic diseases. Skin prick testing was performed in the majority of participants at each follow-up. ${ }^{12-15}$

\section{Eighteen-year follow-up}

The study was approved by Southampton \& South West Hampshire Research Ethics Committee (07/HO504/188) and the protocol registered with ISRCTN (96472018). Of the original 120 participants, 114 (95\%) gave informed consent for the assessment at age 18. The researchers assessing the participants were blinded to their group allocation. As in previous assessment, all participants answered the International Study of Asthma and Allergies in Childhood (ISAAC) core questionnaire ${ }^{17}$ and, where appropriate, reported the type of asthma medication used and answered the Juniper asthma-specific quality-of-life questionnaire.

For 103 participants (48 in the prevention group and 55 in the control group), allergy skin prick testing was performed by a standardised method ${ }^{18}$ to house dust mite (Dermatophagoides 
pteronyssinus), grass pollen mix, tree pollen mix, cat and dog epithelia, Alternaria alternata, Cladosporium herbarum, milk, hens' egg, wheat, soya, cod, peanut and in addition, histamine and physiological saline were used as the positive and negative controls, respectively (Alk-Abello, Horsholm, Denmark).

Exhaled nitric oxide (FeNO) was measured (Niox mino, Aerocrine AB, Solna, Sweden) according to ATS guidelines, ${ }^{19}$ prior to spirometry. Baseline pulmonary function was measured using Koko spirometry software (PDS Instrumentation, Longmont, USA) according to standardised methodology. ${ }^{20}$ Methacholine bronchial challenge was performed in accordance with international guidelines. ${ }^{21}$ In order to compare bronchial hyperresponsiveness where participants did not achieve a $20 \%$ (or more) drop in their $\mathrm{FEV}_{1}$, the dose response slope was calculated. $^{22}$ Induction, processing and analysis of sputum samples were undertaken in accordance with ERS guidelines. ${ }^{23}$

\section{Definitions}

A participant was defined as atopic where (s)he had at least one positive skin prick test to a food or aeroallergen. A skin prick test was defined as positive where the mean weal diameter was $\geq 3 \mathrm{~mm}$ larger than the negative control. Asthma was defined as a positive response to (1) has a doctor diagnosed you with asthma and, either (2) have you wheezed in the last 12 months or (3) are you on inhaled corticosteroids? Atopic asthma was defined by the combination of asthma plus atopy.

Table 1 Asthma, asthma phenotypes and atopy at 18-year follow-up

\begin{tabular}{|c|c|c|c|}
\hline & $\begin{array}{l}\text { Prevention } \\
(\mathrm{n}=56)^{*} \\
\mathrm{n}(\%)\end{array}$ & $\begin{array}{l}\text { Control } \\
(n=58)^{*} \\
n(\%)\end{array}$ & p Value $\neq$ \\
\hline Any current asthma & $6(10.7)$ & $15(25.9)$ & 0.04 \\
\hline Persistent asthma & $3(5.4)$ & $10(17.2)$ & 0.04 \\
\hline Late-onset asthma & $3(5.4)$ & $5(8.6)$ & $0.38 \S$ \\
\hline Remitted asthma & $7(12.5)$ & $5(8.6)$ & 0.50 \\
\hline \multirow[t]{2}{*}{ Ever had asthma } & $13(23.2)$ & $20(34.5)$ & 0.18 \\
\hline & $\begin{array}{l}\text { Prevention } \\
(\mathrm{n}=48) \dagger \\
\mathrm{n}(\%)\end{array}$ & $\begin{array}{l}\text { Control } \\
(n=55) \dagger \\
n(\%)\end{array}$ & p Value $\neq$ \\
\hline Atopic asthma at 18 & $4(8.3)$ & $13(23.6)$ & 0.04 \\
\hline Non-atopic asthma at 18 & $2(4.2)$ & $2(3.6)$ & $0.64 \S$ \\
\hline Any current atopy & $21(43.8)$ & $28(50.9)$ & 0.47 \\
\hline Persistent atopy & $9(18.8)$ & $22(40.0)$ & 0.19 \\
\hline Late-onset atopy & $12(25.0)$ & $6(10.9)$ & 0.06 \\
\hline Remitted atopy & $0(0.0)$ & $1(1.8)$ & $0.53 \S$ \\
\hline Ever been atopic & $21(43.8)$ & $29(52.7)$ & 0.36 \\
\hline Any current HDM sensitisation & $14(29.2)$ & $23(41.8)$ & 0.18 \\
\hline Persistent HDM sensitisation & $6(12.5)$ & $17(30.9)$ & 0.02 \\
\hline Late-onset HDM sensitisation & $8(16.7)$ & $6(10.9)$ & 0.40 \\
\hline Remitted HDM sensitisation & $0(0.0)$ & $1(1.8)$ & $0.53 \S$ \\
\hline Ever been HDM sensitised & $14(29.2)$ & $24(43.6)$ & 0.13 \\
\hline $\begin{array}{l}\text { Any current food allergen } \\
\text { sensitisation }\end{array}$ & $9(18.8)$ & $8(14.5)$ & 0.57 \\
\hline $\begin{array}{l}\text { Persistent food allergen } \\
\text { sensitisation }\end{array}$ & $0(0.0)$ & $1(1.8)$ & $0.53 \S$ \\
\hline $\begin{array}{l}\text { Late-onset food allergen } \\
\text { sensitisation }\end{array}$ & $9(18.8$ & $7(12.7$ & 0.40 \\
\hline $\begin{array}{l}\text { Remitted food allergen } \\
\text { sensitisation }\end{array}$ & $3(6.3)$ & $7(12.7)$ & $0.22 \S$ \\
\hline $\begin{array}{l}\text { Ever been food allergen } \\
\text { sensitised }\end{array}$ & $12(25.0)$ & $15(27.3)$ & 0.79 \\
\hline
\end{tabular}

The bold values in the last column ( $p$ value) indicate statistically significant differences. *Base: all participants in 18-year follow-up.

†Base: participants who underwent SPT and spirometry.

$\neq \mathrm{p}$ Values are from $\chi^{2}$ tests, except those marked §which are from Fisher's exact tests. Persistent, onset at/before 8 years follow-up and still current at 18; late-onset, onset between 8 and 18 years; remitted, onset at/before 8 years but not current at 18 years.
Asthma in childhood is variable in terms of onset, remission and relapse. To test whether the intervention was associated with the different types, we classified participants into one of the following groups: 'persistent asthma' (asthma onset at/ before 8 years and current asthma at 18 years), 'late-onset asthma' (asthma at 18 years but no prior history of asthma), 'remitted asthma' (no asthma at 18 but prior history of asthma) or 'never asthma' (no current or prior history of asthma).

\section{Statistical methods}

Details of statistical methodology are provided in the on-line supplement. Briefly, an intention-to-treat analysis was performed using all available data. The sample size was limited to the original 120 participants who were recruited prenatally 18 years ago. The primary outcome of the current analysis was asthma at 18 years, and longitudinally from 1 to 18 years of age.

Depending on the significance in bivariate analysis, six explanatory variables were tested for inclusion in the binary regression model: (1) group, (2) dual heredity, (3) family history of asthma (at least one parent or sibling with asthma), (4) whether or not the subject was a firstborn child, (5) exposure to smoke in the 2 years preceding the 18-year follow-up and (6) maternal smoking during pregnancy.

To assess the relationship between groups and the different types of asthma (never asthma, persistent asthma, remitted asthma and late-onset asthma), a multinomial logistic regression model was built using the same model-building strategy as for the binary regression model. Longitudinal analysis was undertaken using generalised estimating equations (GEE) with a logit link function and an independent correlation structure. The GEE analysis was based on the 114 subjects who were followed-up at 18 years, as well as at age 1, 2, 4 and 8 (a total of 547 data points).

\section{RESULTS \\ Asthma at $\mathbf{1 8}$ years: cross-sectional analysis}

At the age of 18 years, 114 of 120 (95\%) were assessed; 56/58 (96.6\%) from the prevention group and 58/62 (93.5\%) from the control group (figure 1). The prevalence of asthma was significantly lower in the prevention group compared with the control group $(10.7 \%$ and $25.9 \%$, respectively); the OR was $0.34,95 \% \mathrm{CI}$ 0.12 to $0.96, p=0.04$ ) (table 1 ). The significantly lower prevalence of asthma at 18 years was due mainly to a lower prevalence of persistent asthma rather than late-onset asthma.

The binary logistic regression found that only two variables were significantly associated with asthma at 18 years once other explanatory variables were held constant: group and family history of asthma. The final model contained these two covariates. The odds of asthma at age 18 were 4.33 times greater if there was a family history of asthma (CI 1.37 to $13.74, \mathrm{p}=0.01$ ). Once family history of asthma was held constant, the odds of asthma at age 18 for the prevention group were 0.23 times the odds for the control group (CI 0.08 to $0.70, \mathrm{p}=0.01$ ). In other words, the effect of the intervention was stronger once we adjusted for family history of asthma. We tested for interaction between group and family history of asthma, but this was not significant $(p=0.48)$.

The frequency and severity of asthma symptoms and asthmaspecific quality-of-life scores ${ }^{24}$ were not significantly different between the groups (table 2). Further, there was no significant difference in terms of lung function, bronchial hyperresponsiveness, FeNO or airways inflammatory cells.

Table 3 shows the results of the multinomial logistic regression model. The figures in the table are predicted probabilities, 
Table 2 Symptoms, quality of life, lung function and airway inflammation in participants with asthma

\begin{tabular}{|c|c|c|c|}
\hline Variable & $\begin{array}{l}\text { Prevention (participants } \\
\text { with asthma }=6 \text { ) }\end{array}$ & $\begin{array}{l}\text { Control (participants } \\
\text { with asthma = 15) }\end{array}$ & p Value \\
\hline \multicolumn{4}{|l|}{$\begin{array}{l}\text { Symptoms in the last } \\
12 \text { months }\end{array}$} \\
\hline Wheeze on exertion & $6(100.0 \%)$ & $13(86.7 \%)$ & 1.00 \\
\hline $\begin{array}{l}\text { Wheeze affecting } \\
\text { speech }\end{array}$ & $2(33.3 \%)$ & $5(33.3 \%)$ & 1.00 \\
\hline$>4$ wheeze attacks & $4(66.7 \%)$ & $5(33.3 \%)$ & 0.36 \\
\hline $\begin{array}{l}\text { Sleep affected >1 } \\
\text { night a week }\end{array}$ & $1(16.7 \%)$ & $2(12.5 \%)$ & 0.91 \\
\hline $\begin{array}{l}\text { Asthma quality-of-life } \\
\text { scores }\end{array}$ & $5.06(4.00-6.10)$ & $6.01(5.60-6.50)$ & 0.07 \\
\hline $\mathrm{FEV}_{1}, \%$ predicted & 85.67 (17.39) & $97.55(12.96)$ & 0.11 \\
\hline FVC, \% predicted & $91.80(12.43)$ & $96.50(17.03)$ & 0.55 \\
\hline $\mathrm{FEV}_{1} / \mathrm{FVC}, \%$ predicted & $94.71(16.23)$ & $101.75(7.95)$ & 0.20 \\
\hline PEFR, \% predicted & $95.15(21.77)$ & $100.88(17.24)$ & 0.53 \\
\hline FeNO, ppb & $21.38(1.5)$ & $33.86(2.13)$ & 0.10 \\
\hline Sputum eosinophils, \% & $3.0(1.8-3.5)$ & $1.8(1.1-5.9)$ & 1.00 \\
\hline Sputum neutrophils, \% & $9.5(2.9-16.2)$ & $5.7(1.6-15.8)$ & 0.47 \\
\hline Sputum epithelial cells, \% & $2.8(1.15-6.8)$ & $5.3(2.9-9.9)$ & 0.08 \\
\hline \multicolumn{4}{|c|}{$\begin{array}{l}\text { Numbers are frequencies (\%), means (SD) or median (IOR). } \\
\mathrm{p} \text { Values are Pearsons } \chi^{2} \text { (frequencies) or two-sample t test (means) except for quality of } \\
\text { life and induced sputum results (Mann-Whitney U test). Six and } 14 \text { participants with } \\
\text { asthma in the prevention and control groups underwent spirometry and FeNO (geometric } \\
\text { mean and SD reported). Four and } 10 \text { of them in the prevention and control groups } \\
\text { underwent methacholine challenge, and } 4 \text { and } 7 \text { were able to provide an induced sputum } \\
\text { sample. } \\
\text { DRS, dose response slope; FeNO, exhaled nitric oxide. }\end{array}$} \\
\hline
\end{tabular}

that is, the proportion of the study participants in each group who would have each type of asthma according to the model (thus, each row sums to $100 \%$ ). These results confirm that the association between the intervention and asthma at 18 is almost entirely due to the prevention group being significantly less likely to have persistent asthma; there was no significant association between group and late-onset or remitted asthma, even when family history of asthma was held constant. The predicted probability of persistent asthma among those with no family history of asthma was five times higher in the control group than in the prevention group $(8.5 \%$ and $1.6 \%$, respectively). Similarly, the predicted probability of persistent asthma among those with a family history of asthma was four times higher in the control group than in the prevention group $(28.0 \%$ and $7.0 \%$, respectively).

\section{Atopy and asthma at $\mathbf{1 8}$ years: cross-sectional analysis}

There were no significant differences in the prevalence of atopy, HDM sensitisation or food allergen sensitisation between the groups at age 18 years (table 1). Although atopy was not significantly different between the two groups at 18 years (OR:

Table 3 Results of multinomial logistic regression model: predicted probability of being in each 'asthma' group

\begin{tabular}{lcccc}
\hline & \multicolumn{3}{l}{ Predicted probability of: } \\
\cline { 2 - 5 } & $\begin{array}{l}\text { Never } \\
\text { asthma }\end{array}$ & $\begin{array}{l}\text { Remitted } \\
\text { asthma }\end{array}$ & $\begin{array}{l}\text { Persistent } \\
\text { asthma }\end{array}$ & $\begin{array}{l}\text { Late-onset } \\
\text { asthma }\end{array}$ \\
\hline $\begin{array}{l}\text { Prevention group, no family } \\
\text { history of asthma }\end{array}$ & $90.3 \%$ & $6.1 \%$ & $1.6 \% *$ & $2.1 \%$ \\
$\begin{array}{l}\text { Control group, no family } \\
\text { history of asthma }\end{array}$ & $80.2 \%$ & $6.1 \%$ & $8.5 \% *$ & $5.2 \%$ \\
$\begin{array}{l}\text { Prevention group, family } \\
\text { history of asthma }\end{array}$ & $70.9 \%$ & $15.3 \%$ & $7.0 \% *$ & $6.8 \%$ \\
$\begin{array}{l}\text { Control group, family } \\
\text { history of asthma }\end{array}$ & $47.5 \%$ & $11.7 \%$ & $28.0 \% *$ & $12.9 \%$ \\
\hline$* \mathrm{p}<0.05$. & & &
\end{tabular}

0.75 , CI 0.34 to $1.63, p=0.47$ ), prevalence of atopic asthma was significantly lower in the prevention group (OR: 0.29, CI 0.09 to $0.97, p=0.04$ ) (table 1). This finding led to the hypothesis that the intervention was acting by reducing the effect of atopy in inducing asthma. To test this hypothesis, a binary logistic regression model was run with the interaction between atopy and the group as the sole explanatory variable. The interaction term did not have a significant association with asthma at 18 years, which was unsurprising given the small numbers. The hypothesis is a plausible one, but a larger study would be required to test it properly.

Asthma over childhood and adolescence: Iongitudinal analysis GEEs assessed the association between the prevalence of asthma throughout the length of the study with repeated-measure analysis, adjusted for group, sex, dual heredity, firstborn status, maternal, paternal smoking and pet exposure. The prevention group was significantly less likely to have asthma throughout childhood (OR: 0.51, CI 0.32 to 0.81, $\mathrm{p}=0.04$ ) (figure 2). Males was significantly associated with an increased risk of asthma within this model (OR 1.71, CI 1.11 to 2.6, $\mathrm{p}=0.02$ ), and no other variable was significantly associated with an increased risk of asthma within this model.

Repeated-measure analysis showed that over the length of follow-up there was a significantly lower period of prevalence atopy in the prevention group compared with the control group (OR: 0.42 , CI 0.25 to $0.83, p=0.007$ ) (figure 3 ). The difference between the groups was noticeable from the earliest follow-up at 1 year, and persisted through to 8 years, when the difference had narrowed and became non-significant at 18 years (figure 3 ).

\section{DISCUSSION}

Our study demonstrates a significant and sustained reduction in the prevalence of asthma in participants who underwent a comprehensive food and house dust mite allergen-avoidance strategy in the first year of life. Atopy is a significant factor in the development of asthma. Our analysis demonstrates a significant reduction in the prevalence of atopy and, specifically, HDM sensitisation in the prevention group in early childhood (table 1), resulting in a significant reduction in persistent asthma, and therefore, the difference in asthma prevalence still being significant at 18 years, specifically atopic asthma. There was no significant effect on atopy or asthma developing during adolescence. However, the longitudinal analysis demonstrates an overall significant difference in the prevalence of both asthma and atopy over the duration of follow-up (figures 2 and 3). Further follow-up will determine whether our intervention has successfully prevented the onset of asthma or merely delayed it to later adult life.

The study has several limitations. The number of randomised participants was small, and so the study may not have had adequate power for all the variables tested. However, the finding of a significant difference in the primary outcome measure of asthma prevalence is a valid one, as power is only critical to prevent Type II error where the null hypothesis, of no significant difference between the two groups, is inappropriately accepted. Another limitation is that participants were aware of the group allocation and, hence, reporting bias remains a possibility. However, preventive effect has been consistent throughout 18 years, including asthma treatment prescribed by their physicians. In view of the open design, the control group may have taken measures to reduce allergen level, but that would serve to reduce the difference between the groups. The active intervention stopped at 12 months; however, it is possible that parents in the 


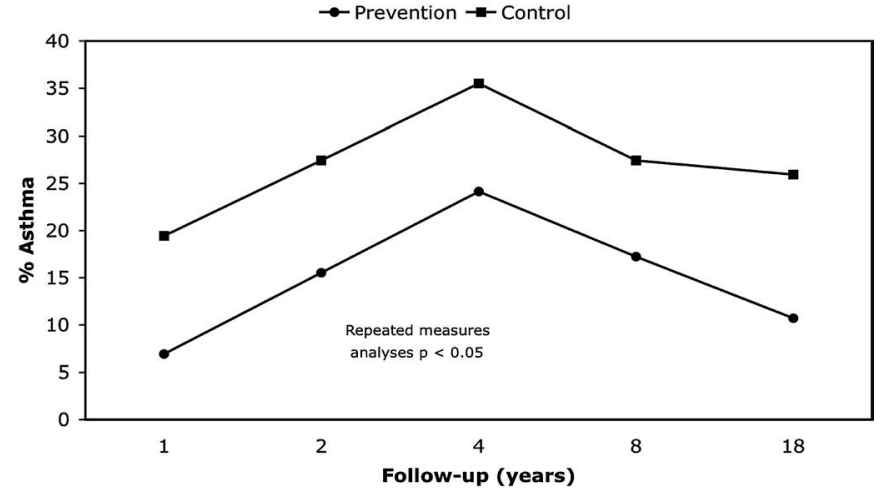

Figure 2 Prevalence of asthma over 18 years of follow-up. Generalised estimating equation-repeated measures analysis, adjusted for first born status, dual heredity, exposure to paternal and maternal smoking and pets in the home.

prevention group may have continued with some allergenavoidance measures. There was concern regarding an underreporting of asthma symptoms by adolescents in the intervention group if they were aware of their group allocation. We asked 23 randomly selected participants regarding their group allocation. Only three could correctly identify their group. Thus, we do not think that response bias influenced the outcome of this study.

The two groups were matched in terms of education, smoking and participation in this study (table E1). While there were significantly more participants with dual heredity in the prevention group and firstborns in the control group, neither of these variables influenced the outcome in either cross-sectional or longitudinal analysis. We did not adjust for multiple testing as the primary outcome variables, that is asthma and atopy, were determined a priori, before this analysis, at the inception of this RCT, and subsequently at every follow-up. ${ }^{12-16}$ Symptoms, lung function and markers of airway inflammation did not significantly differ between patients with asthma in the prevention and control groups (table 2). However, the numbers were small and the possibility of type II error (false negative) cannot be excluded. All we can say is that the intervention reduced the prevalence of asthma globally rather than preventing onset at the milder or severe end of the asthma spectrum.

Our finding of a significant reduction in asthma using the dual intervention of HDM avoidance and dietary modification is unique in terms of the comprehensive allergen-avoidance regime, the overall length of follow-up and the size of the preventive

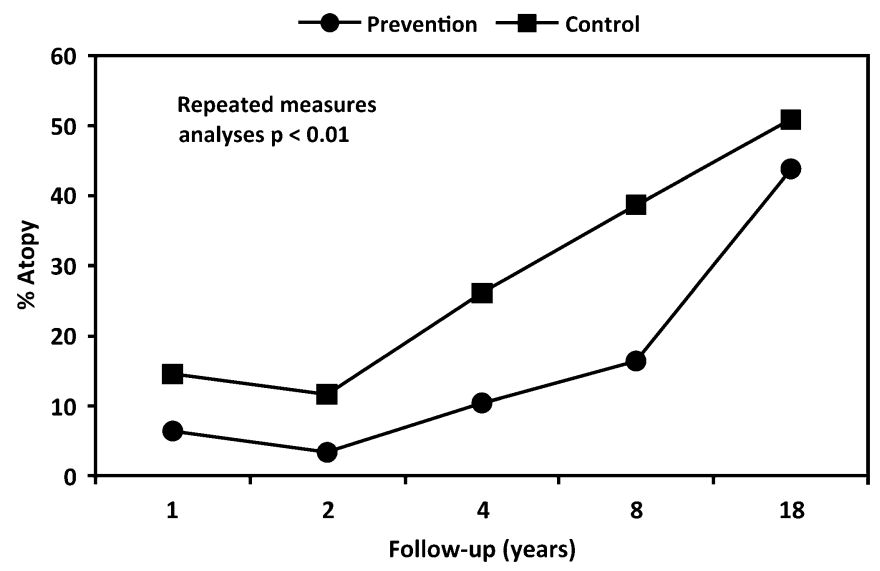

Figure 3 Prevalence of atopy over 18 years of follow-up. Generalised estimating equation-repeated measures, bivariate analysis. effect observed. Other studies using similar, although not the same, multifaceted intervention had some success. The Prevention of Asthma in Children study found that allergen avoidance was associated with a significant reduction in parental reporting of asthma symptoms at 2 years. ${ }^{25}$ The Canadian Childhood Asthma Primary Prevention Study at their 7-year follow-up found a significant reduction in the prevalence of asthma in the intervention group compared with their control group $(14.9 \%$ vs $23 \%) .{ }^{26}$ The requirement for the combination of dietary modification in addition to house dust mite avoidance and the additional need for prolonged breast feeding/delayed introduction of allergens into the infants' diet may account for the lack of success of single-intervention trials of house dust mite avoidance, $^{27} 28$ or dietary modification, ${ }^{29}$ to significantly reduce the prevalence of asthma. Manchester Asthma and Allergy Study is the epitome of single-allergen intervention where extensive mite allergen-avoidance measures resulted in reducing HDM levels to very low levels, and yet, failed to prevent asthma. ${ }^{30}$ This notion is supported by a systematic review, which concluded that multifaceted interventions were effective, at least to some extent, in reducing the development of asthma while single interventions failed to have any effect. ${ }^{31}$

Recent epidemiological observations support the notion of immune tolerance induction, rather than allergic sensitisation following early high-dose exposure to allergen. ${ }^{32}$ So how can we reconcile these observations with the current study where a reduction in allergen exposure seems to be protective? There may be a number of explanations. Most of the data on high-dose exposure being protective comes from foods such as peanut, rather than inhalant exposure. ${ }^{32}$ Thus, the nature of allergen and route of exposure may be important in determining the outcome. $^{33}$ Further, there may be a non-linear relationship between allergen exposure and sensitisation so that very low and high exposures may lead to tolerance, while a moderate level, and/or repeated exposure, may cause sensitisation. ${ }^{34}$ Genetics may offer yet another explanation for our findings. The effect of environmental exposure may depend on the genetic sequence variation, ${ }^{35}$ with opposite outcomes possible following exposure to the same exposure. ${ }^{36}$ Although, the island population is not inbred, it is possible that participants in this study were particularly responsive to the effect of a comprehensive reduction in allergen exposure. A larger, multicentre trial with information on genetic and epigenetic features may answer some of these critical questions.

This is the only study that has shown a persistent and significant reduction in asthma and atopy throughout childhood. Other studies have not shown these benefits, but none of the other trials have replicated the design and methodology of this trial. For a number of reasons, which include small sample sizes and genetic homogeneity, the prevention effect seen in this study may not be generalisable. However, given the heterogeneous nature of asthma, it is unlikely that a single intervention of any kind would be effective in all participants. The significance of asthma prevention is such that further studies are warranted to identify the subgroups where reduction in allergen exposure might be effective.

In conclusion, our study provides evidence that a combined dietary and environmental allergen-avoidance strategy in the first year of life is successful as a primary prevention strategy for asthma in high-risk individuals, with benefits persisting into early adulthood. There is an urgent need to replicate these findings in a large multicentre study with stratification to investigate effectiveness and cost-effectiveness, and the immunological mechanisms underlying this approach. 
Acknowledgements The authors acknowledge the help of all the staff at The David Hide Asthma and Allergy Research Centre in undertaking the 18-year assessment, and the generosity of the participants and their families of the 1990 Isle of Wight prevention cohort in being part of these assessments.

Contributors SHA conceived the idea and worked with all the authors on the plan for recruitment, assessments and analysis, and reviewed and revised draft. MS undertook the recruitment and assessments, performed data entry and initial statistical analysis and wrote the first draft. AN reviewed and revised the statistical analysis. GR, SM and RK helped with the draft revisions. All the authors reviewed and discussed the results, contributed to the manuscript and approved the final version.

Funding Funding was provided by the National Institute for Health Research (Research for Patient Benefit) PB-PG-0906-11015.

Competing interests None.

Ethics approval Ethics approval was provided by NRES Committee South Central-Southampton B.

Provenance and peer review Not commissioned; externally peer reviewed.

\section{REFERENCES}

1. Bousquet J, Dahl R, Khaltaev N. Global alliance against chronic respiratory diseases. Eur Respir J 2007;29:233-9.

2. Steinke JW, Rich SS, Borish L. Genetics of allergic disease. J Allergy Clin Immunol 2008;121(2 Suppl):S384-7.

3. Arbes SJ Jr, Gergen PJ, Vaughn B, et al. Asthma cases attributable to atopy: results from the Third National Health and Nutrition Examination Survey. J Allergy Clin Immunol 2007;120:1139-45.

4. Arshad SH. Primary prevention of asthma and allergy. J Allergy Clin Immunol 2005;116:3-14.

5. Celedón JC, Milton DK, Ramsey CD, et al. Exposure to dust mite allergen and endotoxin in early life and asthma and atopy in childhood. J Allergy Clin Immunol 2007:120:144-9.

6. Greer FR, Scott $\mathrm{H}$, Sicherer A, et al. Effects of early nutritional interventions on the development of atopic disease in infants and children: the role of maternal dietary restriction, breastfeeding, timing of introduction of complementary foods, and hydrolyzed formulas. Pediatrics 2008:121:183-91.

7. Bisgaard $\mathbf{H}$, Hermansen MN, Buchvald $F$, et al. Childhood asthma after bacterial colonization of the airway in neonates. N Engl J Med 2007;357:1487-95.

8. Jackson DJ, Gangnon RE, Evans $\mathrm{MD}$, et al. Wheezing rhinovirus illnesses in early life predict asthma development in high-risk children. Am J Respir Crit Care Med 2008:178:667-72.

9. Holt PG, Sly PD. Prevention of allergic respiratory disease in infants: current aspects and future perspectives. Curr Opin Allergy Clin Immunol 2007;7:547-55.

10. Saglani S, Payne DN, Zhu J, et al. Early detection of airway wall remodeling and eosinophilic inflammation in preschool wheezers. Am J Respir Crit Care Med 2007:176:858-64.

11. Lodge CJ, Lowe AJ, Gurrin LC, et al. House dust mite sensitization in toddlers predicts current wheeze at 12 years. J Allergy Clin Immunol 2011;128:782-8.e9.

12. Arshad SH, Matthews S, Gant C, et al. Effect of allergen avoidance on development of allergic disorders in infancy. Lancet 1992;339:1493-7.

13. Hide DW, Matthews S, Tariq S, et al. Allergen avoidance in infancy and allergy at 4 years of age. Allergy 1996;51:89-93.

14. Hide DW, Matthews $S$, Matthews $L$, et al. Effect of allergen avoidance in infancy on allergic manifestations at age two years. J Allergy Clin Immunol 1994;93:842-6.

15. Arshad SH, Bateman B, Matthews SM. Primary prevention of asthma and atopy during childhood by allergen avoidance in infancy: a randomised controlled study. Thorax 2003;58:489-93.
16. Arshad SH, Bateman B, Sadeghnejad A, et al. Prevention of allergic disease during childhood by allergen avoidance: the Isle of Wight Prevention Study. J Allergy Clin Immunol 2007;119:307-13.

17. Asher M, Keil U, Anderson $\mathrm{H}$, et al. International Study of Asthma and Allergies in Childhood (ISAAC): rationale and methods. Eur Respir $J$ 1995:8:483-91.

18. Dreborg S. Skin tests for the diagnosis of IgE-mediated allergy. Allergy 1989;144 (Suppl 10):31-7.

19. American Thoracic Society, : European Respiratory Society. ATS/ERS recommendations for standardized procedures for the online and offline measurement of exhaled lower respiratory nitric oxide and nasal nitric oxide in adults and children. Am J Respir Crit Care Med 1999:160:2104-17.

20. Miller MR, Hankinson J, Brusasco V, et al. Standardisation of spirometry. Eur Respir J 2005; 26:319-38.

21. American Thoracic Society. Guidelines for methacholine and exercise challenge testing. Am J Respir Crit Care Med 2000;161:309-29.

22. O'Connor G, Sparrow D, Taylor D, et al. Analysis of dose-response curves to methacholine. An approach suitable for population studies. Am Rev Respir Dis 1987; 136:1412-17.

23. Paggiaro PL, Chanez P, Holz 0, et al. Sputum induction. Eur Respir J 2002;37:3S-8S.

24. Juniper EF, Guyatt GH, Epstein RS, et al. Evaluation of impairment of health-related quality of life in asthma: development of a questionnaire for use in clinical trials. Thorax 1992;47:76-83.

25. Schonberger HJ, Dompeling E, Knottnerus JA, et al. The PREVASC study: the clinical effect of a multifaceted educational intervention to prevent childhood asthma. Eur Respir J 2005;25:660-70.

26. Chan-Yeung M, Ferguson A, Watson W, et al. The Canadian Childhood Asthma Primary Prevention Study: outcomes at 7 years of age. J Allergy Clin Immunol 2005; 116:49-55.

27. Maas T, Dompeling E, Muris JW, et al. Prevention of asthma in genetically susceptible children: a multifaceted intervention trial focussed on feasibility in general practice. Pediatr Allergy Immunol 2011;22:794-802.

28. Horak F, Matthews S, Ihorst $\mathrm{G}$, et al. Effect of mite-impermeable mattress encasings and an educational package on the development of allergies in a multinational randomized, controlled birth-cohort study-24 months results of the Study of Prevention of Allergy in Children in Europe. Clin Exp Allergy 2004; $\mathbf{3 4 : 1 2 2 0 - 5}$

29. von Berg A, Filipiak-Pittroff B, Krämer U, et al; GINIplus Study Group. Preventive effect of hydrolyzed infant formulas persists until age 6 years: long-term results from the German Infant Nutritional Intervention Study (GINI). J Allergy Clin Immunol 2008:121:1442-7.

30. Woodcock A, Lowe LA, Murray CS, et al. Early life environmental control: effect on symptoms, sensitization, and lung function at age 3 years. Am J Respir Crit Care Med 2004:170:433-9.

31. Van Schayck CP. Is there any role for allergen avoidance in the primary prevention of childhood asthma? J Allergy Clin Immunol 2007:119:1223-8.

32. Du TG, Katz Y, Sasieni P, et al. Early consumption of peanuts in infancy is associated with a low prevalence of peanut allergy. J Allergy Clin Immunol 2008;122:984-91.

33. Lack G. Epidemiologic risks for food allergy. J Allergy Clin Immuno 2008; 121:1331-6.

34. Tovey ER, Almqvist C, Li Q, et al. Nonlinear relationship of mite allergen exposure to mite sensitization and asthma in a birth cohort. J Allergy Clin Immunol 2008; 122:114-18.

35. Simpson A, John SL, Jury F, et al. Endotoxin exposure, CD14, and allergic disease an interaction between genes and the environment Am J Respir Crit Care Med 2006; 174:386-92.

36. Kerkhof M, Daley D, Postma DS, et al. Opposite effects of allergy prevention depending on CD14 rs2569190 genotype in 3 intervention studies J Allergy clin Immunol 2012;129:256-9. 